\title{
Fractura de pene. A propósito de dos casos
}

\section{Penile fracture. A report of two cases}

\section{Sr. Director:}

Se presentan dos casos clínicos de fractura peneana, el segundo de ellos asociada a lesión uretral.

El caso clínico 1 es de un paciente varón de 41 años que acudió a Urgencias por haber notado, mientras realizaba el acto sexual, un chasquido peneano con inmediato dolor y detumescencia peneanos. En la exploración se evidenciaba un hematoma peneano, sin participar el periné. No asociaba uretrorragia ni dificultad miccional. Se practicó un sondaje uretral a su llegada a Urgencias, sin complicaciones, y la exploración quirúrgica a las 6 horas reveló incisión subcoronal, que evacuó el gran hematoma procedente del cuerpo cavernoso izquierdo, con lavado de este, sutura de la túnica albugínea y revisión del cuerpo esponjoso, que estaba indemne. El paciente permaneció sondado durante dos semanas, con retirada de la sonda, sin incidencias. En la primera revisión al mes de la intervención el paciente ya había recuperado la erección, sin presentar secuelas estéticas.

El segundo caso clínico corresponde a un paciente varón de 34 años que acudió a Urgencias por dolor, uretrorragia e incapacidad para la micción espontánea tras escuchar un chasquido peneano en el transcurso del acto sexual. A la 


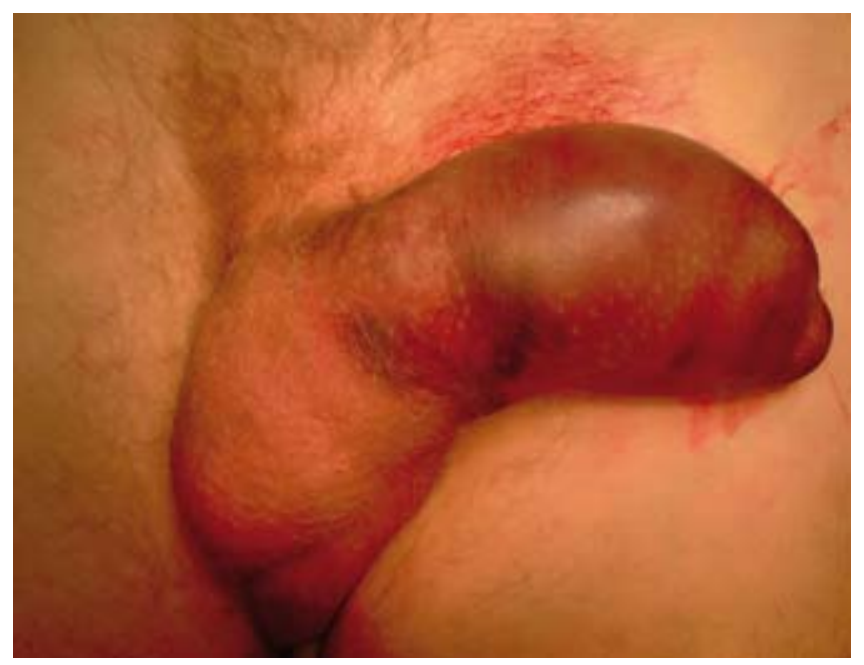

Figura 1 - Gran hematoma subcutáneo con desviación peneana.

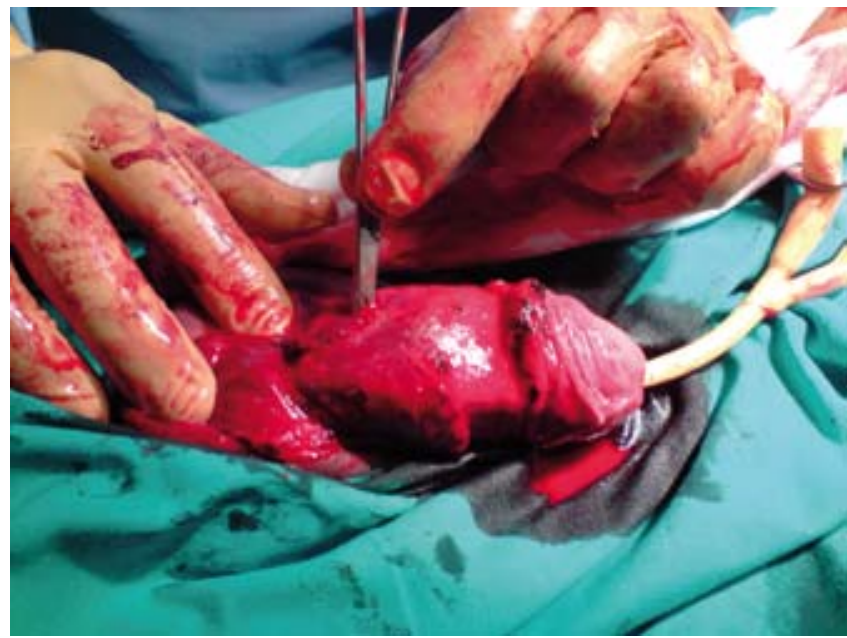

Figura 2 - Solución de continuidad sobre el cuerpo cavernoso derecho. Introducción de pinza para una mejor visualización del orificio.

exploración clínica se evidenciaba una tumescencia y hematoma peneanos con desviación lateral de este. Presentaba dolor espontáneo y a la palpación. No se apreciaba globo vesical, pero sí incapacidad para la micción. El resto del periné no presentaba alteraciones (fig. 1). El sondaje uretral no fue posible, y ante la sospecha de fractura de cuerpos cavernosos asociada a lesión uretral y aumento progresivo del hematoma, se decidió revisión quirúrgica inmediata: incisión subcoronal, con apertura de cubiertas hasta evacuar el gran hematoma que surgía del orificio de rotura del cuerpo cavernoso derecho (fig. 2). Se apreció una pequeña erosión de la uretra, tras la cual se visualizaba la sonda Foley. Se limpió el hematoma mediante lavado del cuerpo cavernoso con suero fisiológico. Se suturó la albugínea con puntos reabsorbibles de 00 y cierre por capas y de la piel, dejándose la sonda para tutorización uretral. Durante los primeros 4-5 días postoperatorios persistió la uretrorragia, que cedió con compresión.
A su vez, el paciente consiguió erecciones completas a partir del tercer día.

En la primera revisión a las tres semanas se le retiró la sonda, orinando de forma espontánea.

La fractura de pene es una patología en la que se produce la rotura de uno o los dos cuerpos cavernosos, pudiéndose asociar o no a una lesión uretral, sobre el pene en erección. Es una entidad cuya incidencia real se desconoce, debido a que muchos pacientes no consultan por ser una situación embarazosa. La fractura puede acompañarse de rotura uretral hasta en un $20-30 \%$ de las ocasiones, según las series ${ }^{1-4}$, y cuando esto ocurre suele haber rotura bilateral, con una clínica de uretrorragia, aparición de sangre en el meato uretral, hematuria, dificultad para el sondaje o imposibilidad para la micción.

La etiología más frecuente de la fractura es el coito (33$58 \%)^{4}$, ya que durante la erección el espesor de la albugínea es menor; a ello se le añade la menor elasticidad de la túnica albugínea y el aumento de la presión intracavernosa, lo que hacen que el pene sea menos resistente a la angulación y, por tanto, que se facilite el mecanismo de rotura. El diagnóstico de esta patología se basa en la anamnesis y exploración clínica. Algunos autores recomiendan la realización de pruebas de imagen sólo cuando se sospeche una lesión uretral ${ }^{5}$, otros, en cambio, recomiendan la cistoscopia flexible intraoperatoria $^{6}$. En nuestra experiencia nos decidimos por la exploración quirúrgica bajo anestesia, sin previas exploraciones complementarias (CUMS, uretroscopia).

El tratamiento de elección es la reparación quirúrgica inmediata en las primeras 36 horas ${ }^{7}$; sólo algunos pacientes se beneficiarían de un tratamiento conservador. En nuestro primer caso demoramos la intervención quirúrgica por la estabilidad del paciente, ya que pudo realizarse el sondaje uretral sin complicaciones (no sospechamos lesión uretral). En el segundo caso, ante la sospecha de lesión uretral, se desestimó el intento de sondaje y se practicó la exploración quirúrgica. Pese a que algunos autores recomiendan la disección de la uretra en estos casos, para realizar una buena anastomosis sin tensión, nosotros sólo reparamos la rotura del cuerpo cavernoso con sutura externa uretral. Los resultados obtenidos en los dos casos han sido excelentes, sin presentar secuelas en ambos pacientes, que como ya sabemos pueden ir desde la incurvación peneana (10-30\% de los tratamientos diferidos) $)^{7}$ hasta erecciones dolorosas, fístulas uretrocutáneas, fístula cavernosa, infección, placa fibrótica, estenosis y disfunción eréctil.

\section{B I B L I O G R A F Í A}

1. Llarena Ibargueren R, Villafruela Mateos A, Azurmendi Arin I, García Fernández J, Pertusa Peña C. Fractura de pene con rotura asociada de uretra. Arch Esp Urol. 2006;59(7):732-6.

2. García Marchiñena P, Capiel L, Juárez D, Liyo J, Giudice C, Gueglio G, et al. Penile fracture with associated retra lesion: case report and bibliographic review. Arch Esp Urol. 2008;61(8):936-9.

3. Roy M, Matin M, Alam M, Suruzzaman M, Rahman M. Fracture of the penis with urethral rupture. Mymensingh Med J. 2008;17(1):70-3. 
4. Martínez Ruiz J, Pastor Navarro H, Carrión López P, Giménez Bachs JM, Donate Moreno MJ, Virseda Rodríguez JA. Fractura de cuerpos cavernosos. Serie de casos. Actas Urol Esp. 2008;32(6):599-602.

5. Maruschke M, Lehr C, Hakenberg OW. Traumatic penile injuries - mechanisms and treatment. Urol Int. 2008;81(3):367-9.

6. Kamdar C, Mooppan UM, Kim H, Gulmi FA. Penile fracture: preoperative evaluation and surgical technique for optimal patient outcome. BJU Int. 2008;102(11):1640-4.

7. Juaneda Castell B, Montlleó González M, Ponce de León Roca X, Gausa Gascón Ll, Caparrós Sariol J, Villavicencio Mavrich H. Fístula uretrocavernosa por fractura penena. Actas Urol Esp. 2008;32(10):1043-5.
L. M. Moratalla Charcos*, T. Pastor Navarro, M. Beamud Cortés y J. M. Osca García Servicio de Urología, Hospital Universitario Doctor Peset, Valencia, España

${ }^{*}$ Autor para correspondencia. Correo electrónico: luzmoratalla@comv.es (L. M. Moratalla Charcos) 